\title{
LAS RELACIONES COMERCIALES DE BARCELONA CON EL NORTE DE ÁFRICA (SIGLO XIII)
}

\author{
Carmen Batlle • Elisa Varela
}

Las actividades de los mercaderes catalanes recibieron un impulso en dirección al Mediterráneo después del desastre de Muret (1213), cuando quedaron cerradas las posibilidades de expansión ultrapirenaica y se incrementaron, en cambio, en el comercio marítimo.

Los catalanes ampliaron el número de sus viajes hacia Mallorca y Sicilia, que eran las escalas obligadas en el itinerario normal hacia el Norte de Africa o «Romania», mientras seguían acudiendo a la España musulmana y conservaban algunos de sus mercados en el Sur de Francia a pesar de los acontecimientos políticos adversos para ellos.

Al mismo tiempo la burguesía barcelonesa enriquecida por el comercio poseía elevadas sumas capitalizadas para disponer libremente de gran parte de las mismas e invertirlas en negocios, como las comandas, dirigidas a todo el ámbito del Mediterráneo haciendo gala de su espíritu mercantil y de una innegable continuidad.

En las costas del Norte de Africa las circunstancias no siempre fueron favorables y los negocios catalanes en sus puertos sufrieron los avatares de cualquier comercio en tierra enemiga, tenía tal consideración todo país islámica desde el punto de vista cristiano y en todos los conceptos. En principio, si se hubieran acabado las disposiciones papales, apenas se habrian realizado transacciones, pero la realidad era distinta, puesto que los mercaderes se arriesgaban a cualquier peligro, material o espiritual, después de comprobar las posibilidades de lucro ofrecidas por las zonas maritimas de la España musulmana y del Magreb. 
Dentro del estado de hostilidades permanentes, que era la situación política normal entre la Corona catalano-aragonesa y los respectivos emires o sultanes, se aprecian altibajos marcados de forma positiva por los tratados de amistad y de forma negativa por los apresamientos de naves por parte de los enemigos. La situación se complica aún más en momentos difíciles para los monarcas catalanes, como lo son sin duda los conflictos con Jaime II de Mallorca, la lucha por Sicilia y más aún la cruzada francesa contra Túnez.

No vamos a insistir en el tema político ya suficientemente tratado por Dufourcq, sólo nos limitaremos a aportar noticias sobre los mercaderes catalanes y sus negocios en los puertos norteafricanos, sin comentar las referentes a la España musulmana, aunque tanto los puertos de Almería y Málaga como las islas de Mallorca y Sicilia forman parte de la ruta de las naves con destino a Berbería y así consta en multitud de comandas y otros negocios, el del vino por ejemplo.

\section{LAS SOCIEDADES FAMILIARES}

Una forma de negociar muy frecuente en Barcelona es la formación de sociedades familiares integradas por un miembro capitalista y otro gestor o varios gestores. Es natural que se utilice el mismo sistema en los negocios africanos y así lo hacen los Banyeres, Albareda, Bou, Llull, etc.

Parece que los Banyeres son los primeros de todos ellos, y por este motivo les dedicaremos, casi exclusivamente, el presente trabajo.

Pronto se dedican a los negocios en el Norte de Africa (la primera fecha corresponde a una comanda de 1239) (1), y entre ellos encontramos representados a los dos grupos mencionados: capitalistas y gestores. No podía ser de otro modo cuando al capitalista le era imposible convertirse en gestor de su propia fortuna por ser un eclesiástico. Entonces entregaba dinero a otro miembro de la familia, como lo hizo el canónigo Guillem de Banyeres, que en 1260 entregó en comanda 27 libras barcelonesas invertidas en 127 besantes y 6 millareses a su pariente Guillem de Banyeres que se dirigía a Berberia (2).

Por otro lado los miembros jóvenes de las familias llevaban a cabo su aprendizaje en el campo de los negocios como factores de sus padres o parientes de más edad, y así lo hizo Martí de Banyeres, hijo de Albert, en Mallorca (1244), donde entregó un préstamo al armador Poses, del que hablaremos en el apartado sobre las naves. El capital paterno manejado, por el jo- 
ven, en esta etapa de formación consta en el testamento de su padre como su parte de la herencia.

El más activo y el más rico de los Banyeres, Ramón, calificado de draper, participa de los dos aspectos analizados durante su larga vida, que desde el punto de vista del negocio empieza, según nuestras noticias, con la comanda destinada a Túnez en junio de 1239. A mediados del siglo ya tiene una gran fortuna acumulada en sus manos, que le permite llevar a cabo la más espectacular de sus empresas, la compra de alumbre en una operación con implicaciones en Tremecén, Castilla y Montpeller. La realiza con un importante sarraceno llamado Bonambran (Abu Imran en árabe), embajador del sultán de Tremecén en Barcelona, Ramón pudo invertir 4000 besantes en 571 quintales y medio de alumbre de Castilla comprado al musulmán comprometiéndose a suministrarle armamento de Montpeller, término con el que podía designar los aparejos y demás equipamiento de una nave o armas. Como en esta operación, cuya escritura es de 30 de junio de 1250, el negociante difícilmente podía actuar solo mediante una suma tan elevada de dinero, se asoció con Ramón Ricard, ciudadano barcelonés embajador de Jaime I en tierras africanas, que pagó la tercera parte del alumbre el 27 de julio siguiente (3).

El mismo Banyeres estuvo en estas tierras acaso con motivo de la compra del alumbre, cuyo pago debía hacer efectivo en Tremecén; aquí residió por lo menos unos meses de fines de 1250 aprovechando el viaje para otros negocios. En esta ciudad le entregó 120 besantes de planta el nauclerio Arnau Despuig(4); se trata seguramente de una operación de crédito con cambio de moneda.

Un poco más tarde, el 13 de marzo siguiente, y para liquidar una operación similar pero más complicada Ramón pagó 100 besantes a Arnau Guardiola, que antes se los había entregado en Tremecén por Guillem Burget (5).

La operación principal -la del alumbre- y las transacciones complementarias debieron dar buen resultado, cuando en junio de 1254 los socios Banyeres y Ricard volvían a actuar, pero esta vez en un escenario un poco distinto, en Túnez. También ahora ambos adquirían una mercancía (150 quintales de cera a 32 besantes el quintal) a un sarraceno enviado del sultán tunecino y a Guillem de Montcada, alcaide de la milicia catalana, con 500 besantes de Ricard, que Banyeres transportaría de Barcelona a Túnez, desde donde se dirigiría con la cera a Barcelona o a Aigües Mortes y luego a:Montpeller para venderla, y desde allí regresar a su ciudad natal (6). 
La presencia en dichos negocios de los nombres de los embajadores reales y del alcaide de la milicia nos permite entrever un transfondo político y un trasiego de capitales con' posibles implicaciones del mismo monarca.

A partir de esta fecha Ramón permanece en Barcelona, donde recibe mercancías enviadas desde Bugía por Jaume d'Albareda, con quien le unía un parentesco por alianza, al igual que le sucedía con Bernat Sesfonts.

Su sobrino Jaume, hijo de Arnau de Banyeres, siguió sus pasos pero con mayor modestia: el 16 de enero de 1253 daba a Arnau Gilbert una comanda consistente en 150 sueldos implicados en tres sacos de avellanas cuando partía hacia Orán en el leño de Mayol (7) Al cabo de cinco años justo se hallaba en ultramar y con motivo de tan larga ausencia tuvo que ser substituido en la tutoría de un sobrino; parece que nunca volvió. Mientras, otros parientes se dedicaban más a Mallorca y al sur de Italia, como Martí de Banyeres, hijo de Albert, que negociaba en la isla, donde se hallaba el 20 de abril de 1244, fecha de la concesión de un préstamo a Berenguer de Poses, la elevada suma de 61 libras menos 4 sueldos melgoreses, que éste invirtió en aparejar su nave llamada «Paradís» (8). Otros realizaban el mismo tipo de negocio, el de banqueros, en el Sur de Italia, y en Sicilia.

Más adelante Jaume de Banyeres, draper, invertía en una comanda entregada el 20 de marzo de 1274 a Bernat Martorell y Pere Mataró, que partían con destino a Málaga y Berbería en el leño de este último(9), siguiendo el camino trazado por Ramón, de quien fue primero socio y luego heredero.

En la órbita de los Banyeres hay que considerar a los Albareda. Entre Barcelona y Bugia, y seguramente otros puertos, los hermanos Albareda con sus socios y colaboradores llevaban a cabo muchos negocios, de los cuales sólo conocemos una pequeña parte, la que estaba pendiente de conclusión a la muerte de Jaume. Contaban para ello con unos medios de transporte seguros, como era la nave patroneada por Berenguer y también el leño de su cuñado Guillen de Tarragona, de los cuales Jaume de Albareda poseía unas partes ( $1 / 4$ del leño).

Todos ellos pertenecían al grupo de los mercaderes viajeros, navegantes y gestores de comandas, pero dentro de la misma familia los miembros más jovenes actuaban como factores de los mayores, que poseían el capital necesario, cuyo origen desconocemos. Hallamos a Jaume ya instalado en Bugía e integrado en diversas sociedades dedicadas a la venta de tejidos y en relación con Ramón de Banyeres, a quien envía por medio de Berenguer Juan y Pere de Malla 300 pieles (boquines), 4 «pondera de orchicana» que 
pesaban 21 quintales y 61 rótulos; por esta partida Ramón sólo había entregado 10 doblas de oro a Pere de Albareda antes de 1258.

Como Ramón de Banyeres había estado en Tremecén a fines del año 1250 y luego residía en Barcelona, Jaume podría ser su socio o factor encargado de mandarle mercancías del país.

Ademas de los mercaderes mencionados hasta aquí, estudiados en otro trabajo, otros procedentes de diferentes poblaciones catalanas debían acudir a tierras africanas en la época estudiada, pero no podemos concretar su origen como hemos hecho con los citados más arriba, porque en general no consta en la documentación. Son muchos los negociantes gestores de comandas con nombre catalán que firman sus contratos en Barcelona antes de partir, o los residentes en el Norte de Africa que aparecen como testigos de documentos escritos allí por notarios catalanes (10), pero al lado del nombre casi nunca hallamos el lugar de procedencia y por eso desconocemos su lugar de nacimiento.

\section{LAS COMANDAS Y LOS PRODUCTOS COMERCIALIZADOS}

La comanda es, sin duda, el sistema más utilizado por los comerciantes barceloneses en relación con el Norte de Africa por tratarse de un método muy adaptado a las circunstancias. Lo afirmamos a pesar de haber localizado solamente 30 documentos conservados desde el siglo XIII, exactamente entre 1239 y $1300(11)$.

La mayoría de ellas, 17, están fechadas entre 1270 y 1278, siendo los años mejores 1271 con cinco y el siguiente con cuatro. Si bien, el escaso número de documentos no permite sacar muchas conclusiones, es significativa esta frecuencia y también la aparición de comandas desde 1239 y su desaparición a partir de 1291 .

Si observamos la distribución mensual, percibimos una mayor concentración de operaciones durante los meses de la primavera, que parece ser la época del año más favorable, para estos viajes algo largos, la mayoría dirigidos hacia Berbería.

Primavera: $517 \%$

Verano: 17 '2 \%

Otoño: $17^{\prime} 2 \%$

Invierno: 10 '3 \% 
El destino de las comandas no se concreta mucho, ya que la mayoría, 17, van dirigidas a Berbería, seis a Túnez, dos a Ceuta, tres a Trípoli, una a Orán, otra a Bugía y una a tierra sarracena. El total es de 32, porque en dos casos el destino es doble, por ejemplo Túnez y Trípoli.

En cuanto a los negociantes, se dividen en comandantes o capitalistas y comanditarios o gestores, que son mucho más numerosos que los primeros: 44 y 19.

Entre los capitalistas destaca la familia de los Banyeres con cinco personas, Ramón, Guillem, Jaume, Joan y su socio Ramón Ricard, seguida por los Malla, Pere y su viuda, los Sesfonts, padre e hijo, y dos Malet. También merece ser destacado el número de comandas hechas por cada uno de ellos: el capitalista que invierte más es el banquero Jaume Ferran con el dinero de sus clientes: 6 , seguido por Bernat Sesfonts y el peletero Malla, y su viuda, con 4.

Los nombres de los comanditarios son más numerosos y sólo se repiten en pocos casos, los cuales corresponden a patronos de nave: los socios $\mathrm{Pe}$ re Remer y Berenguer de Sarrià tres veces y Domènec Llull, Pere de Trípoli y Guillem Ferrer dos veces. Entre los 44 gestores predominan los patronos y hombres de mar, como Arnau Despuig, nauclerio, que siempre llevaban mercancías propias y de otros para sacar el máximo provecho de la nave; pero aparte se concretaba el nombre del armador del barco que realizaba el viaje.

El valor de las comandas no es muy alto: la media es de 26 libras, ya que la suma total de las 29 recogidas se eleva a 767 libras. La mayoría, 9 , oscilan entre 20 y 30 liras, luego hay entre 7 entre 10 y 20 libras y sólo una sobrepasa las 70 libras, lo cual representa los valores máximos de inversión de los catalanes en todo el ámbito del Mediterráneo occidental.

En la zona norteafricana los inversores demuestran ciertas preferencias: en Túnez invierten 134 libras frente a 110 en Orán y 102 en Ceuta, dejando para el final Trípoli y Bugía con 14 y 12 respectivamente.

Los productos comercializados por medio de este sistema, tanto los de ida como los de vuelta del viaje, eran mercancías de precio elevado y de escaso volumen, que era lo ideal para cargar en el tipo de naves de la época. Permitían su fácil transporte en naves relativamente de poca capacidad, formando cargamentos de diversos propietarios y de composición muy variada, que cabían bien en las bodegas de los buques, excepto en el caso del trigo 
de Sicilia, transportado al Norte de Africa por naves catalanas a fines del siglo en un cargamento único.

Algunas veces la mercancía consistía en numerario destinado a la compra de lo mejor y más útil que viera el gestor, como lo prometió Pere de Trípoli a Jaume Ferran cuando éste le entregó 80 mazmudinas de oro, equivalentes a 40 libras de Barcelona, para su viaje en la nave de Ramón Salembre hacia Berbería; en otro caso la comanda consistió en 7 libras y media de moneda de terno de Barcelona implicadas en 15 mazmudinas de oro rexadias (12). La comanda también podía ser mixta e incluir una parte en metal o numerario y otra en mercancías, como una que comprendia 27 libras y 3 sueldos y medio de Barcelona invertidas en 10 marcos y 7 onzas de millareses y 26 libras barcelonesas implicadas en dos guarniciones completas de jinete y de caballo (13).

Las monedas transportadas eran utilizadas como una mercancía más del comercio, permitiendo así la transferencia de fondos, y pueden considerarse como un préstamo marítimo.

Como en la época anterior, durante casi toda la Edad Media el Norte de Africa continuó siendo un granero para la Europa mediterránea y por lo tanto el comercio de cereales entre sus puertos y los de la Corona de Aragón fue constante y, en general, en dirección a estos últimos. Esto no excluye que en algunas ocasiones los cereales - trigo, cebada, y mijo- se hallen en naves catalanes de viaje hacia Berbería, junto con otros alimentos, sin cumplir los decretos papales prohibiendo el comercio de productos alimenticios y estratégicos, como lo deseaba Jaime I (14). Incluso el geógrafo árabe lbn Said señala la exportación cerealística de Mazagan hacia la Península (15).

En los tratados o treguas entre los monarcas respectivos hay cláusulas sobre este punto, por ejemplo en el de 1271, en el cual se estipula que los cereales introducidos en Túnez no pagarán diezmo. Más adelante, en el de 1302, se indica que, como siempre, el trigo de Marruecos destinado a Barcelona pagará a la salida 3 doblas por cahiz.

Las comandas permiten precisar las mercancías cargadas con más frecuencia a bordo de naves en viajes de ida y en algunos de vuelta. Como ya hemos aludido al trigo seguimos con lo productos alimenticios, entre los cuales destaca el vino exportado al Norte de Africa desde Barcelona o desde Sicilia y sur de Italia. De esta última procedencia era el vino encargado por Guillem Colom, de Manresa, que en 1256 contrató con otro catalán el transporte y la descarga de 400 a 500 migeroles a 3 besantes y 8 millareses por migerola, en Alcoll (16). 
Desde Barcelona a Berbería varios gestores llevaban vino en comanda, como Ramón de Sant Martí, que invirtió en 20 cahices de vino los 100 besantes entregados por el canónigo barcelonés Bertran Delfí (17), y algunos gestores más, como los de Pere de Malla, de su viuda y otros (18), sin que conste nunca la clase del vino transportado.

Otros productos alimenticios son los frutos secos, de los que se especifican avellanas en sacos, ametllons en faxiis, higos en espuertas, el arroz, el azúcar y las especias, por lo menos pimienta y azafrán.

A pesar de lo expuesto los productos manufacturados predominan de modo evidente en las exportaciones catalanas y entre ellos destacan los tejidos, con más draps que teles, y fustanes de algodón o con listas de seda (19).

Las telas de la comanda de Joan de Banyeres pueden proceder de su propio taller de pañería o de fustanería, como se precisa otras veces. También constan «telis et draperia» en la comanda de la viuda Malla (1278). Son de lana, lino, algodón e incluso cáñamo, según se precisa en otras comandas, los tejidos elaborados en Lérida y otras poblaciones catalanas; de los extranjeros se indica su origen: biffa de Sant Denis o París, stamfort de Arrás, seda "yuria», y seguramente el presset rojo (20). Estas son las telas que tenían en sus obradores Jaume d'Albareda y los pañeros catalanes establecidos en Túnez y Bugía.

Entre los productos manufacturados destacan los garnatxes o vestidos de piel o pieles de armiño, guarniciones de caballos, los cifos o copas de plata, papel, cuchillos de Vic, etc. Otros objetos exportados son: laca, índigo, algodón, bermellón, etc.

Algunos de estos productos constan en gran cantidad, como 69 canas de stamfort de Arrás (21), 160 canas de tela de lino, 102 canas de fres o galón de telar ancho, 33 canas de fres de telar estrecho, 7 docenas de estameña de Banyoles, 30 canas de fres de lis d'aur, o sea, con flores de lis de oro, de Montepeller (22).

\section{LOS MEDIOS DE TRANSPORTE}

Siendo el mar el medio natural para el desarrollo de toda la actividad comercial, proliferaron las empresas de navegación tanto en Barcelona como en puertos africanos. En ambas costas para traslado de hombres y mercancías se fletaban naves nacionales y extranjeras, cuya presencia en Barcelona provocó la concesión de privilegios proteccionistas por parte de Jaime l. 
Las embarcaciones llamadas naus, llenys, galeras, barcas son las más utilizadas. Toda esta potencia naval la vemos tanto al servicio de empresas guerreras como de las comerciales, por ejemplo en la conquista de las Baleares -1229- y de Valencia -1238-; ambos hechos crearon dificultades en el tráfico normal con Berbería, ya que no será hasta 1250 cuando aparezcan otra vez abundantes testimonios del comercio catalano-africano, de forma constante y continuada.

Barcelona se convierte, como bien dice Vicens Vives (23), en un centro cómodo de relación con los paises del Islam.

Este progresivo aumento de las construcciones navales y del tráfico comercial marítimo de la ciudad se refleja en la documentación por la presencia de socios capitalistas y de marinos, como patrones, co-patrones y propietarios de naves, como Pere Cabré, Pere Salembe, Berenguer y Pere Sarrià seguramente de la misma familia del almirante Bernat de Sarrià, marinero y guerrero impetuoso, según apunta Dufourcq (24), nauclerios (notxers) como Huguet Puig y Arnau Puig, que en documento de 26 de enero de 1250 recibe de Ramon de Banyeres 120 besantes de plata; cómitres, marineros, serviciales aparecen frecuentemente, como en el contrato de flete de 15 de septiembre de 1266 de Túnez a Barcelona (25). También constan el escribano de la nave de Arnau de Sanaüja y los de otros buques, que equivalía a un notario.

El equipamiento y el mantenimiento de una nave durante un viaje tan largo como el de Barcelona a las costas de Berbería, con escalas, requería un verdadero capital, que algunos hombres de mar conseguían reunir con dificultades; a pesar de ello las ganancias solian compensar los desembolsos y préstamos. Si bien éstos eran normales en la reparación de naves, como hemos visto, no habíamos encontrado nunca el préstamo de utensilios necesarios para la navegación hasta hallar el caso de Bernat de Sant Pau y Berenguer Laic, dueños de un leño, que en enero de 1241 partía de Barcelona hacia Berbería con un ancla prestada por Bernat Calafat, a quien debían devolverla a su regreso (26).

Por experiencia propia o ajena todos veian la ganancia segura, hasta el punto que el mismo monarca participaba en el negocio directamente con sus naves, una de ellas mandada por Pere Ferrer, el cual se hallaba en Túnez vinculado con Reguers, el cónsul de los catalanes de dicha ciudad (27).

A mediados del siglo tener una nave en Túnez dispuesta para el transporte de mercancías era un buen negocio porque existía demanda. Los catalanes aprovecharon bien estas circunstancias favorables y entre ellos el bar- 
celonés Pere Bonfill. Este preparaba su viaje en septiembre de 1256, fecha en que hallándose en Barcelona contrató a un joven gerundense por dos años, durante los cuales le alimentaría y vestía con 10 canas de stamfort de Arrás, dos piezas de cota de piel de conejo y anualmente con dos pares de calzas, tres pares de zapatos, dos camisas y dos calzoncillos, y además cobraría por sus servicios un salario de 60 sueldos de Barcelona (28).

Ya en Túnez Bonfill y su socio Pere de Llobregat, de Mallorca, explotaban la nave «Sant Miquel», una tarida, que adquirieron a dos genoveses, Ansaldo Ricci y Ansaldo Portonario, el 26 de mayo de 1258. Cerrado el trato en la alhóndiga nueva de los genoveses, los catalanes pagaron 1250 millareses, quedando dos partes para Bonfill, una sexta parte para los genoveses y la última sexta parta para Llobregat, incluidas en el reparto la jarcia y las barcas de la tarida, con sus árboles y timones. Todo se llevó a cabo en presencia de Ramon de Girona y Pere de Prat, que ya habían contratado los servicios de dicha nave por adelantado para ir a Montpeller (29), antes de formalizarse su compra, según se deduce de la existencia del compromiso de fletamiento el 24 de mayo.

Los socios aprovecharon bien su nave, porque además de este viaje a Montpeller, pronto concretaron otro también con punto de partida y regreso a Túnez en agosto del mismo año bajo ciertas condiciones (30).

De las formas de explotación comercial de las naves, encontramos la del comú en el documento de 9 de enero de 1272: «en el lleny del nostre comú». De este común formaban parte el buque, en este caso el «lleny», y las mercancías, que en este viaje eran telas, laca, doblas de oro y otras cargadas en la embarcación para un determinado viaje -aquí Denia y Berbería- (31).

Esta situación suponía la formación de una comunidad o masa común con las mercancías que constituían el cargamento de un buque y el buque mismo. Este conjunto o masa de bienes se valoraba, y a veces se dividia en partes alícuotas, como en el viaje del 8 de mayo de 1271 «consta dicho común de 16.250 sueldos y está dividido en 16 partes y cuarta", y en el viaje a Berbería en el «lleny» de Pere de Sarrià, Guillem Sant Feliu y socios (32).

El buque entraba en la comunidad por su valor, pero éste podía variar y variaba de un viaje a otro, tal vez dependiendo, entre otras cosas, de su estado de navegabilidad - aparejos-, según apunta Nuria Coll (33) y, las mercancías por el suyo también, que era aportado, generalmente, en comanda por diferentes capitalistas o por una sociedad, como hace Jaume Ferran para el viaje efectuado el 8 de mayo de 1271 con los socios de su taula (34). 
Los gestores de la comunidad eran los propios co-patrones del buque. El 11 de mayo de 1271 Berenguer de Sarrià y Pere Remer, en su leño y de sus socios, son los encargados de llevar a cabo la operación comercial del común - de telas, laca, aceite, paños de lino y otras mercancías- valorado en 1.078'5 libras de Barcelona de terno, en viaje a Berbería (35). De este modo encontramos dos comunidades superpuestas, gestionadas por las mismas personas: la comunidad ordinaria y más o menos permanente de los copropietarios de la nave y la extraordinaria y ocasional del viaje que formaba el buque con su cargamento.

El desarrollo de la operación era el normal de la comanda «missa in comuni». La cuarta parte restante del lucro total, llamada quart diner, quedaba para los gestores, que eran los patrones de la nave.

La forma de fletamento ordinaria se halla claramente especificada en el mencionado contrato de flete firmado por Pere Bonfill en Túnez el 15 de septiembre de 1266 con un mallorquín: «tot quintaratas mercium, scilicet, coriorum bovum, buchinarum...”.

El «Llibre del Consolat de Mar» impone ciertas condiciones que deben cumplir el patrón y los fletadores, y son: -el patrón de la nave no debe cargar las mercancías en otro buque distinto del fletado, y por ello se consigna el nombre del mismo, tal como aparece en el flete de 24 de mayo de 1258, en el viaje de Túnez a Montpeller con la nave «Sant Miquel» de Pere Bonfill, ciudadano de Barcelona,(36) y en el documento de 15 de septiembre de 1266, en el viaje de Túnez a Barcelona «cum ligno meo vocato Sancto Angelo, de portu Tunicii apud Barchinona...», bajo la responsabilidad de los daños y perjuicios que sufran tales mercancias; el patrón tiene la obligación de mantener el aparejo y pertrechos del buque en perfectas condiciones, y no puede despedir a oficiales y marineros hasta finalizado el viaje, sin consentimiento de los fletadores. En el documento ya citado de 1258 la nave debe estar «bene exarcista et amarinata cum viginti marinariis»; además debe cargarse a bordo la cantidad de mercancía pactada en el contrato, que es en el caso de este flete firmado en Túnez: pieles de buey, boquines, alumbre, orchicana, comino, dátiles, cera, pimienta, gengibre e índigo hasta 670 quintales.

Si el mercader no embarcaba la cantidad de mercancías acordada, el patrón podía exigirle el flete sobre el vacio por la cantidad no cargada, y si la cantidad cargada excedía la que acordaron podía cobrarle al mercader otro tanto como lo acordado, según las leyes del Consulado de Mar. Creemos. que por este motivo se estipula en una cláusula del contrato que dicha cifra de quintales puede llegar a aumentarse en una tercera parte dentro de un límite de quince días. 
Además del pago del flete los mercaderes tenían otros gastos, como la carga de las mercancias, que sólo en caso de hallarse en despoblado corria a cargo de los marineros, si bien a costa de los fletadores y no de la nave. También corrían a cargo de los fletadores los gastos de estiva de las mercaderías a bordo, salvo disposición contraria.

A la recepción de las mercancías a bordo deben ser inscritas en el cartulario, por el escribano de la nave. Si queda mercancia no declarada al escribano en dicho momento, debe serlo cuando la nave salga del puerto, de lo contrario quedan exentos de toda responsabilidad tanto el escribano como el patrón.

En el «Llibre del Consolat del Mar» respecto al viaje de la nave, consta que siempre que se realice el consignado en el contrato de fletamento, hay libertad de ruta y escalas, mientras no se opongan a los fletadores, con las excepciones derivadas de los casos de fuerza mayor: restricción del rey o sultán, temporales, enemigos o corsarios.

Estos contratos suelen establecer las estadías o tiempo de plancha, que es el tiempo que debe invertir el buque en la carga y descarga, durante el cual el patrón debe esperar a los cargadores y a los fletadores, como aparece en el flete de 1266 «...promitens vos expectare et esse me expeditum a Tunicio per totum mensem septembris, in quo nunc sumus»; y las sobreestadías, es decir, el tiempo que exceda de las estadías ocasiona, según el «Llibre del Consolat de Mar», la exigibilidad de la pena impuesta para este caso en el contrato de fletamento, y por dicha estipulación penal hacen responsables a los cargadores de los daños y perjuicios sufridos por la nave a consecuencia de la demora, que deben ser fijados por dos prohombres de mar.

La cuantía del flete se pacta en una cantidad por quintal, bien sea en pleno o en vacío, en el flete de 1266 «...pro quolibet quintale quinque milarenses argenti fini...». En el flete de 1258, como se cargan mercancías diversas, el precio varia de cuatro millareses para el quintal de alambre, seis para el de pieles de buey, orchicana, dátiles, cera, pimienta y gengibre, a siete millareses para las boquines, "prout decenderit de ferro», comino e índigo. El momento de su pago es el de la descarga de las mercancías, si no se ha establecido un plazo.

Nada se opone al pago anticipado del flete, con pacto de su adquisición por el patrón, como vemos en el contrato de fletamento de 15 de septiembre de 1266, en el que se pacta el pago del flete antes de que la nave zarpe de Túnez: «...Ad hec nos Petrus Bonifilii et Petrus Januarii convenimus et promit- 
timus tibi dicto Bernardo Ferrarii, solvere et deliberare...dictum nauleum...ad tuam voluntatem et mandatum, antequam a Tunicio recedamus...", si bien no se especifican las condiciones de adquisición del flete por parte del patrón.

En el «Llibre del Consolat del Mar», todavía encontramos otras modalidades de fletamento, la más importante de las cuales es el llamado «a escar» o precio alzado, que consiste en fletar la nave uno o varios fletadores, obligándose a pagar en concepto de flete un precio alzado; éste podía ser el caso expuesto en la siguiente reclamación.

Se trata de la protesta presentada por dos hermanos ante el rey por no haber cobrado la cantidad exigida por el flete de una nave para realizar viaje a Túnez: 200 doblas de oro del Amir pidieron Nicolau y Pere Fàbrega al caballero Jofre de Pontils, que todavía no las había pagado el 11 de abril de 1292, cuando intervino el monarca Jaime II, seguramente por tratarse de un caballero integrante de la milicia catalana en el Norte de Africa (37).

No sorprende la cuantía de estos contratos de flete si recordamos el precio de un barco y los gastos de mantenimiento y de reparación.

Las naves aparejadas valían una fortuna, algo menos los leños como el de Pere Ferrer, en el que cabian sólo ocho marineros, un servicial y además quince personas; y las naves como la de Pere Bonfill costaban aún más, éstas tenían 20 marineros, por eso podían servir como garantía de un préstamo, por ejemplo en el caso de la barca de Arnau Emeric el 19 de febrero de 1332 (38). Este Eimeric hizo muchos viajes a los puertos africanos, pero en 1257 lo realizó como embajador de Jaime I a Túnez y regresó al año siguiente consiguiendo el rescate de cautivos, que volvió a vender como esclavos o por los menos fue acusado de hacerlo ante el rey, que le perdonó. En esta hazaña le acompañó su pariente Bernat Eimeric, que ya se hallaba ausente de Barcelona a mediados de diciembre de 1256 (39).

Como se aprecia en los viajes de estas naves, el comercio estaba polarizado entre los puertos importantes: por un lado Túnez, Bugía, Ceuta, Orán, hasta Safi en el Atlántico, por otro Barcelona y Montpeller, y por fin, Ultramar, hasta Acre, lo que daba al comercio marítimo la especial característica de su organización en expediciones redondas de ida (entrada) y vuelta (eixida), con escalas naturalmente sobre todo en las islas, y con mercancias que a veces constan en la misma comanda.

Del análisis de las 30 comandas especificadas en el apartado correspondiente sacamos algunas conclusiones relativas al transporte marítimo, a pesar de que en seis no consta el tipo de barco; la mayor parte son leños, 17, seguidos por las naves, 5 , y 2 barcas. 
La euforia perdurará con numerosas interrupciones debido a la piratería, a acontecimientos políticos, guerras, etc. Todas ellas circunstancias ya estudiadas (40). Como recuerda Dufourcq, los tratados de paz eran solamente treguas, puesto que el estado normal de las relaciones entre cristianos y musulmanes era la guerra, por lo que reinaba gran inseguridad en los puertos norteafricanos (41). A pesar de todo a mediados del siglo era tan frecuente para los catalanes dirigirse a Túnez que se halla consignado como ejemplo de viaje en las «Costum de Tortosa» (1272-1279) en el apartado relativo al cambio marítimo (42).

Sin duda, los viajes se desarrollaron con mayor seguridad después de quedar abierto a la navegación cristiana el estrecho de Gibraltar, en el sentido de restablecerse el tráfico normal entre el Mediterráneo y el Atlántico, que tiene lugar hacia 1277, fecha del inicio de los viajes de los genoveses a Flandes, realizados de forma regular desde 1289.

En conjunto, según el citado historiador (43), la suma de tantas acciones políticas y comerciales llevadas a cabo por los catalanes en el Norte de Africa desembocó en un verdadero imperialismo por su deseo de comprar los productos africanos enumerados más arriba y por el de vender los productos manufacturados y alimenticios, junto con su objetivo de redimir cautivos cristianos y de devolver allí los esclavos sarracenos ya rescatados.

Ya de vuelta las naves catalanas traían a Barcelona algunos productos concretos, bien del país o bien de paises vecinos, como el alumbre de Castilla adquirido por Ramon de Banyeres al embajador de Tremecén. El mismo mercader compró cera en gran cantidad, 150 quintales, que era uno de los productos africanos más apreciados. Procedentes de Ceuta y de Fez es uno de los objetivos catalanes, que la cargan en sus naves para almacenarla luego en Barcelona, por ejemplo en la tienda de Guillem d'Abella, cambista barcelonés, el 15 de marzo de 1287; el banquero tenía en esta parte de su propia casa una fortuna invertida en doce cargas de cera de Fez y 30 cargas más, al peso de Barcelona, cuyo origen no precisa (44). Parece que abunda más la cera de Ceuta, de donde la trabajo Bernat de Ripoll, pariente y socio de Pere de Caldes, por lo menos en esta operación (45).

Gracias a una operación comercial de Jaume d'Albareda sabemos que envió a Barcelona desde Bugía 300 pieles, boquines, y más de 21 quintales de orchicana. Por desgracia en las comandas consta muy pocas veces el cargamento de vuelta y no podemos valorar su importancia respecto a las mercancias importadas a los puertos africanos. 
Aunque no figuren en las comandas, creemos que los productos exóticos tenían su parte en el cargamento de los barcos cuando los hallamos en manos de algunas ricas barcelonesas, como la esposa de Bernat Marques. En sus testamentos mencionan como un objeto de su propiedad por proceder de su dote la jaula de papagayo; si mencionan la jaula es que el pájaro se hallaba o se había hallado en ella y su origen sólo puede ser muy lejano.

A modo de conclusión podemos decir que, tanto en la misma ciudad como durante sus desplazamientos hemos podido seguir a estos negociantes y hombres de mar y hallarlos solos o acompañados por familiares, llenos de vida o enfermos mientras dictaban sus últimas voluntades en Montpeller, Mesina, Bugía y Constantinopla.

Nos interesa destacar su interés por el Norte de Africa que hemos procurado documentar.

Conocida la política catalana en esta zona, ahora ha sido posible confirmar los resultados con la presencia de numerosos negociantes en Túnez y Bugía, donde desarrollaban sus actividades en las alhóndigas reales en relación con los integrantes de las milicias cristianas al servicio de los sultanes. Se aprecia una estrecha correlación entre la situación política y la actividad comercial en las etapas siguientes: favorable a principios del siglo, otra muy buena después de 1250 y más o menos hasta 1267 y diversas alternativas posteriores marcadas por las conquistas de los benimerines, que obtuvieron la eficaz colaboración de naves catalanes en la ocupación de Ceuta (1275) (46).

Durante los años buenos los hombres de Barcelona, Manresa, Vic, Llejda, etc. organizaron empresas, captaron comandas, aparejaron naves hacia puertos norteafricanos, vendieron aquí mismo productos locales e importados y transportaron mercancías desde Túnez a Sicilia o Montpeller. A mediados del siglo es apreciable el recorrido de naves catalanes según una ruta triangular: Barcelona y Mallorca, Túnez y Montpeller. El transporte afectaba a género como el alumbre y la cera, comercializados en grandes cantidades, que desde la última de dichas ciudades eran distribuidos a los centros de las ferias francesas y de allf hasta el norte de este país y Flandes.

La suma de tantas acciones políticas y comerciales llevadas a cabo por catalanes en el Norte de Africa desembocó en un verdadero imperialismo, según Dufourcq, (47) por su deseo de comprar los productos del país y por el de vender los géneros manufacturados y alimentos, junto con su objetivo de redimir cautivos cristianos y de devolver alli los esclavos musulmanes ya rescatados. 
Aunque sólo hemos indicado Salé como límite suroeste de los viajes de las naves catalanas, es necesario precisar que acaso podían llegar más al sur, hasta Togo, adonde iban los mallorquines a fines del siglo XIII en busca de esclavos, oro, marfil, etc. Conocíamos este destino de naves de Mallorca, (48) pero ahora podemos precisar la participación de catalanes en una empresa tan lejana, puesto que el 28 de abril de 1281 Jaume de Prat se embarcó en Barcelona en la barca de Guillem de Gaià y sus socios con destino a Ibiza para ir desde esta isla a Togo. Jaume, cuyo oficio desconocemos, era el gestor de una comanda por lo menos: 52 sueldos y medio de buena moneda barcelonesa de terno invertidos en cuchillos y 10 sueldos «en uno capite fustonorum», tela de Guillem de Prat, acaso hermano del viajero, siendo el comandante Bonanat de Soler (49).

No nos atrevemos a situar el Togo de nuestros documentos en el país africano del Golfo de Guinea, por la revolución que representa en el tema de los descubrimientos, pero el topónimo ya mencionado sale con grafía muy clara. Podría tratarse del «Tegon» situado en las costas de Berbería y mencionado en el Atlas de los Cresques.

En la ruta africana, como en la de Sicilia, la balanza comercial parece ser favorable a Barcelona, que es exportadora, mientras los barceloneses son importadores en la ruta de Ultramar (50).

En general, vemos que las naves barcelonesas seguían circuitos cerrados con inicio y fin en Barcelona, como el triangular ya señalado entre esta ciudad y Mallorca, los puertos norteafricanos y luego Montpeller, o el recorrido más largo hasta Ultramar. Naturalmente eran distintas y más cortas las rutas de las naves dedicadas al transporte que llevaban trigo siciliano a Génova, Pisa o Montpeller, trigo sardo a Pisa, vino desde Túnez a Sicilia, caballos de Aigües Mortes a Túnez, etc.

En este tráfico es reconocida la importancia de la flota catalana independiente o colocada al servicio de otras potencias, que tiene un buen papel en la trabazón de relaciones entre todos los países ribereños del Mediterráneo occidental (51).

Conectada con la red marítima y completando el tráfico mediterráneo con ụn enlace hacia el Atlántico, se hallaba una ruta excepcional para los catalanes, puesto que la tenemos documentada una sola vez, y aún referida a una comanda, que representa la inversión más cuantiosa de todas las comandas catalanas conocidas. Es la ruta que unía el Mediterráneo, por Narbona en este caso, con Inglaterra exactamente vía río Garona, por Tolosa (52). 
En cambio era mucho más normal la conexión de los puertos, desde donde era fácil distribuir las mercancias hacia el interior, con las poblaciones catalanas y las de los demás países de la Corona de Aragón por medio de rutas terrestres y fluviales. La distribución corría a cargo de mercaderes especializados, distintos de los dedicados al comercio marítimo a larga distancia, que se dirigian hacia las ciudades donde el incremento de la capacidad de consumo ofrecía un buen mercado.

No es posible conocer los barceloneses que recorrían las principales rutas terrestres por falta de documentación, por eso resultan tan importantes unas comandas inéditas referidas a un mismo mercader llamado Guillem Amenller. Son tres de 1283 a 1286, gracias a las cuales vemos confirmado el reparto desde Barcelona de mercancias importadas, entre ellas las especias, aunque no se especifique la composición del cargamento, siguiendo una ruta mixta, marítimo-terrestre o fluvial.

La primera fue contratada el 25 de septiembre de 1283 entre Guillem Amenller, ciudadano de Barcelona e hijo de Pere Amenller de Tarrassa, y Castelló Anchorario, que tendría el oficio de hacer anclas; constaba de 15 libras de moneda barcelonesa perpetua de terno llevadas por el gestor, o sea Amenller, desde Barcelona a Tortosa y Zaragoza con mucha libertad, como quisiera, por mar, tierra o agua dulce, o sea navegando por el Ebro, o incluso a los reinos de Aragón y de Valencia y devolverla a Barcelona en cualquier leño o barca (53).

Más o menos el mismo objetivo: Tortosa, Lérida, Zaragoza y el reino de Valencia, tenía el mismo gestor al año siguiente, aunque también se le ofrecía la posibilidad de ir a Perpinyà, con una comanda de 50 libras de la misma moneda barcelonesa pertenecientes al cambista Guillem Pere Dusay, ciudadano de Barcelona. La suma se hallaba invertida junto a las mercancías del gestor, que era un verdadero especialista del reparto de productos desde dicho puerto y desde Tortosa. Aquí volvía el 11 de diciembre de 1286 con 15 libras de Guillem Feliu, zapatero barcelonés (54).

De este modo vemos que, en general, Amenller recorría en comandas - las expuestas han de ser una mínima parte- una ruta en parte marítima hacia Tortosa y luego fluvial hasta la capital Zaragozana por el Ebro, o por el Segre si era hasta Lérida, y en parte terrestre o fluvial hasta Zaragoza, aunque podia seguir hacia Valencia o incluso ir a Perpinyà, según sus conveniencias o la posibilidad de hallar un mejor mercado. Esta era la más importante de las rutas hacia el interior, siendo las demás meras ramificaciones de la misma hacia la costa, por ejemplo de Vilafranca del Penedès hacia Sitges o a partir del puerto de Salou en dirección a Lérida. 
Por todo ello Barcelona resulta un verdadero centro de distribución de mercancías, tanto de los productos naturales del país, por ejemplo azafrán, vino, aceite, almendras, y de los manufacturados aquí -los cuchillos exportados a Togo-, como de los importados previamente. De estos últimos, unos eran destinados a la producción local, por ejemplo el algodón de Sevilla y de Sicilia servía para la elaboración de fustanes; mientras otros, sobre todo las especias, eran distribuidos siguiendo las rutas indicadas.

Al mismo tiempo circulaba el capital, puesto que los banqueros iban a los mismos centros comerciales, como los Banyeres, Dusay y Llull, presentes en Montpeller, Aix en Provenza, Marsella, Génova, Reggio, etc. para financiar sus propios negocios y los de sus compatriotas, extremo que es muy importante destacar.

De momento es difícil poder precisar más en el aspecto humano y tampoco hay grandes posibilidades en el económico, aunque el hallazgo de nuevas fuentes puede permitir dar un paso adelante en un futuro próximo. 


\section{NOTAS}

(1) MADURELL-GARCIA SANZ. Comandas comerciales barcelonesas de la Baja Edad Media, Barcelona, $1973, n,{ }^{\circ} 3$.

(2) El comanditario es calificado de laico para distinguirlo claramente del capitalista. (Archivo de la Catedral de Barcelona, perg. 1-6-3175, 25 de agosto de 1260).

(3) En el contrato escrito en Barcelona por el notario Guillem Rosell ante Guillem Mercader, Bernat Pinxeres y Pere Vives, el sarraceno, que firma en árabe, indica la venta de $\mathbf{5 0 0}$ quintales de alumbre por 3.500 besantes y promete a Banyeres que en caso de pérdida del armamento la indemnización delante de sus garantizadores Berenguer Ermengol y Bernat Mataró. Además alude a un documento anterior relativo a 1.500 besantes y a 2.000 para el armamento que debe adquirirse en Montpeller, todo a su riesgo y fortuna: «Si...ipsa armamenta amitterentur, nihileminus, tenear mittere in tuum posseres emptas de 5.000 bisanciis pro obligatione dictorum $D$ quintalle de alum».(ACB, perg. 1-6-1608). En cambio, en el trato estipulado con Ricard, Banyeres indica el número de 571 quintales y medio de alumbre castellano y al precio de 4.000 besantes pagaderos en Trémecen, acabando por ceder sus derechos en la tercera parte y nombrar procurador suyo a Ricard; aquí se alude a Berenguer Ermengol y a Pere Ferran como garantizadores. Banyeres firmó con su propia mano ante el notario Guillem Rossell y los testigos Guillem Burget y Pere Vives (perg. 1-6-3695). Como MIRET i SANS, J. «Un missatgé de Yarmorasen rey de Tremecen a Jaume |», BRABLE, 8, 1915-16, pp. 48-51, utilizó el primer documento sin indicar su procedencia, DUFOURCQ lo citó en L'expansió catalana a la Mediterrània occidental, segles XIII i XIV, Barcelona, 1969, pp. 118 y en La vie quotidiene dans les ports méditerranéens au Moyen Age (Provence-Languedoc-Catalogne, Paris, 1975, p. 114. Ahora podemos aportar su situación concreta en ACB.

(4) Documento publicado por SAYOUS. Els Metodes comercials a la Barcelona medieval, Barcelona, 1975, doc. 19. En éste y en el documento siguiente se precisa que Ramon de Banyeres es hijo del difunto Albert de Banyeres; véase el árbol genealógico en BATLLE, C. "La familia i la casa d'un draper de Barcelona, Burget de Banyeres (primera meitat del segie XIII)», Acta Medievalia, 2, 1971, pp. 69-91.

(5) Lo escribió el notario Jaume Despuig ante Pere de Manresa y Bernat Calvera (ACB, perg. 1-6-846).

(6) Banyeres tendría la cuarta parte del lucro, como en cualquier comanda normal, aunque ésta era una operación de más envergadura (MADURELL-GARCIA. Comandas...op. cit., doc. 6).

(7) ACB, perg. 1-6-3271.

(8) GARCIA SANZ-FERRER. Assegurances i canvis maritims medievals a Barcelona, Barcelona, 1983, doc. n. ${ }^{\circ} 12$.

(9) ACB, perg. 1-6-2916. Transcrito en apéndice.

(10) Una excepción es Pere Mercader, de Vic, testigo de un documento del 13 de septiembre de 1258 escrito en Túnez (perg. 1-6-2973). También conocemos la procedencia de Rubí 
(Vallés) y de los hombres de la misma familia Rubi presentes en Tremecén entre 1258 y 1265, porque llevan el nombre de su pueblo.

(11) Unas han sido publicadas por MADURELL-GARCIA. $n .^{\circ} 24,29,31,36$ etc. y otras son inéditas, pero casi todas proceden de $A C B$, excepto unas pocas del fondo Marqués de Monistrol del ACA.

(12) Documento del 7 de junio de 1268 (MADURELL-GARCIA. Comandas...op. cit., n. ${ }^{\circ} 24$ y 25), y el documento de 22 mayo de 1268.

(13) Ibid., n. ${ }^{\circ} 18$.

(14) Se halla el trigo con aceite, frutos secos y especias en viaje del 2 de mayo de 1270 hacia Sicilia y Túnez. Una de estas prohibiciones de exportación se halla en ACA, C. reg. 95, fols. $108 \mathrm{v}-109$.

(15) VERNET, J. Marruecos en la geografía de Ibn Saïd, Tetuán, 1953, I-II, p. 253.

(16) Perg. 1-6-2256 comentado ya en el presente trabajo y transcrito en el apéndice documental.

(17) El 25 de abril de 1268, habiendo muerto el canónigo, sus albaceas recuperan 70 besantes de la comanda pagados por Pere Bonfill, el armador de nave ya citado, ante el notario $\mathrm{Pe}$ re de Cardona (perg. 1-6-2727).

(18) El vino consta en cargamento junto con otras mercancías en 1270 y 1278 (MADURELLGARCIA. Comandas...op. cit., n. ${ }^{\circ} 28$ y 42 , pp. $171-72$ y 184-85.

(19) Comanda de 1271 (MADURELL-GARCIA. Comandas...op. cit., n. ${ }^{\circ} 34$ ).

(20) Comanda del 26 de julio de 1274 (ACB, perg. 1-6-110).

(21) Comanda de 1269 hacia Túnez (MADURELL-GARCIA. op.cit., n. ${ }^{\circ} 26$ ).

(22) Son mercancías de gente de Vic en comandas hacia Túnez (CARRERAS CANDI. "Notes dotzecentistes d'Ausona", Boletín de la Real Academia de Buenas Letras de Barcelona, 5, 1909-10, p. 475).

(23) VICENS VIVES. Historia Económica, p. 139.

(24) DUFOURCQ. L'expansió...op. cit., p. 15.

(25) Doc. ACB, perg. 1-6-39 de 15 de septiembre de 1266, publicado por GARCIA SANZ, Arcadio. «Fletamentos catalanes medievales", Historia, instituciones, Documentos, Sevilla, 1978, doc. 1, pp. 249-50, copiado también en nuestro apéndice documental.

(26) Contrato del 18 de enero de 1241 ya comentado en el capítulo sobre las naves (1-6-01).

(27) Ferrer es testigo del contrato de Reguers y Pere Bonfill en agosto de 1258 (1-6-1541), y es procurador del mismo Reguers para recuperar el dinero que le debe Adarró el 5 de junio de 1261 (1-6-2851). El rey le permitió edificar una alhóndiga en Barcelona, DUFOURCQ. «Les Consulats catalans de Tunis et de Bougie au temps de Jacques le conquérant», AEM, 3, 1966, p. 478.

(28) Contrato del 14 de septiembre de 1256 (pergs. 1-6-2981).

(29) Documentos transcritos en el apéndice (pergs. 1-6-1682, 1303).

(30) El 6 de agosto de 1258 los dos socios se comprometen a cargar mercancías de Berenguer de Reguers, que pagará por el flete 6 millaresas y medio por quintal barbaresco. (1-6-1541, transcrito en apéndice).

(31) ACB, perg. 1-6-524. MADURELL-GARCIA. Comandas...op. cit., n. ${ }^{\circ} 36$ citan otro ejemplar.

(32) MADURELL-GARCIA. Comandas...op. cit., n. ${ }^{\circ} 31$.

(33) COLL, Nuria. "Aportación al estudio de los patrones y de la propiedad de las naves en Cataluña en la Baja Edad Mediam, Homenaje a Jaime Vicens Vives, Barcelona, 1965, I, pp. 391-392.

(34) MADURELL-GARCIA. Comandas...op. cit., n. ${ }^{\circ} 31$

(35) MADURELL-GARCIA. Comandas...op. cit., n. ${ }^{\circ} 32$

(36) Contrato del 24 de mayo de 1258 transcrito en el apéndice documental (ACB, perg. 1-61303). En este documento se halla una cláusula muy original referente a parte de la carga: "prout decenderit de ferro", cuyo sentido no queda claro.

(37) En esta fecha el rey escribió en Barcelona tres cartas a favor de Nicolau Fabrega, que actuaba en nombre propio y como procurador de su hermano para reclamar la deuda en Túnez, se hallaba el deudor. La primera está dirigida a Cervià de Riera, a quien encarga 
la presentación de Nicolau el rey de Túnez, y en caso de que Jofre no quiera pagar, Riera deberia dar consejo, auxilio y favor al reclamante. La segunda, dirigida al deudor, incluye noticia de que Jofre debía a Pere Fàbrega 675 doblas de oro del Amir de un préstamo. La tercera va dirigida a Guillem Fava, cónsul de los catalanes en Túnez, que deberá acompañar a Nicolau ante el rey tunecino y ayudarle en todo lo posible. (ACA, C, reg. 98, fol. $22 v)$.

(38) Documento publicado por GARCIA-FERRER. Assegurances...op. cit., n. ${ }^{\circ} 9$. También el n. ${ }^{\circ} 10$ es un caso parecido.

(39) El 18 de diciembre su esposa Suau, por hallarse él en Túnez, firma en el documento del establecimiento de unas tierras de su parellada a un judio (1-2-678). DUFOURCQ. L'expansió...op. cit., pp. 54,86 y 87.

(40) DUFOURCQ. L'expansió,..op. cit., pp. 59-64, 77-79, 94 y ss.

(41) DUFOURCQ. “Chrétiens et musulmans», AEM, 10, pp. 210 y ss. SHNEIDMAN. L'imperi catalano-aragonès (1200-1350), Barcelona, 1975, II, pp. 55-57, resume los avatares políticos y establece unas etapas.

(42) GARCIA-FERRER. Assegurances...op. cit, p. 43.

(43) DUFOURCQ. "Liaisons», p. 111.

(44) En su testamento Abella deja las 12 cargas a su nieta Esclaramunda, hija de Bernat Desdaurats y de Berenguerona d'Abella, y las 30 a su hija Agnès en concepto de legítima paterna junto con otras cosas y propiedades (ACB, PA 4-8-87).

(45) Caldes tenía 45 besantes invertidos en la carga de cera, que a su muerte pasó a manos de su madre Berenguera Bou el 25 de septiembre de 1270 (ACB, perg. 1-6-3736).

(46) DUFOURCQ. «Vers la Méditerranée orientale et l'Afrique», en Jaime l y su época, Zaragoza, 1979 , pp. 5-24.

(47) DUFOURCQ. «Liaisons maritimes...», Cuadernos de Historia Económica de Cataluña, XX, 1979, p. 111.

(48) RIERA, A. «La "Llicencia per a barques", de 1284. Una font important per a l'estudi del comerc exterior mallorquí del darrer quart del segle XIII», Paventia, 2/2, Barcelona, 1980, p. 64 .

(49) El gestor se compromete a invertir el precio obtenido por la venta de estos artículos junto con sus propias cosas y a pagar según se estipula en todos los documentos similares, ante el notario público de Barcelona Berenguer Guilabert y los testigos Pere de Prat, cuchillero, que puede ser el artífice de cuchillos exportados, y Guillem de Montagut (Archivo particular del castillo de Sant Genís de Vilassar, A 23, 1-123). Transcrito en apéndice.

(50) GARCIA SANZ-FERRER. Assegurances...op. cit., I, Barcelona, 1983, pp. 62-63.

(51) MELIS, F. «L'area catalano-aragonese...", IX Congreso de Historia de la Corona de Aragón, I, Nápoles, 1978, p. 202.

(52) Se trata de una comanda de Berenguer de Bonastre del 24 de noviembre de 1273 gestionada por Ramon de Vilardell, que la entrega a dos gestores, Bernat de Caderita, seguramente barcelonés y Benet de Fanjaus, occitano al parecer: 113 libras y 18 sueldos y 8 dineros de Barcelona invertidos en 3 cargas, 2 quintales, 1 arroba y 2 libras de cera y 3 quintales, 3 arrobas y cuarto de gengibre; de esta suma Bonastre tiene 56 libras, 19 sueldos y 4 dineros y el resto pertenece a Vilardell (Según el inventario de los bienes de Bonastre conservado en el archivo particular del castillo de Sant Genís de Vilassar, cuya noticia agradecemos a Coral Cuadrada).

(53) El notario es Berenguer Llobet, como en tantos documentos comerciales, y los testigos son Guillem de Vila y Arnau Meragues (Archivo particular del castillo de Sant Genís de Vilassar, perg. 1,16).

(54) La comanda del 4 de junio de 1284, que podía ser devuelta al comandante en cualquier barca, fue escrita por el mismo notario público ante Guillem de Sant Martí y Pere de Soler. La última fue escrito por el mismo Llobet ante Pere de Soler y Arnau Aguiló. Aquí el gestor apunta la posibilidad de que esta comanda la gestione él mismo o un enviado suyo (íbid., pergs. 1.5 y 1-2-98, que agradecemos también a Coral Cuadrada). 



\title{
APÉNDICE DOCUMENTAL
}

\author{
-1 - \\ 1256, noviembre, 4, Túnez.
}

Contrato estipulado entre Bernat de Riusec, de Manresa, y Guillem Colom y Bernat de Rubi: el primero se compromete a traer 400 o 500 «mitgeroles» de vino del sur de Italia a Alcoll al precio de 3 besantes y 8 millareses por «mitgerola».
A. C.
B., perg. 1-6-2256.

Hoc es translatum fideliter factum. Sit omnibus notum quod ego Bernardus de Rivosicco, de Minorisa, vendo tibi Guillelmo Columbi et Bernardo de Rubi et vestris sociis quadrigentas migerolas usque quingentas migerolas de bono vino de Pati vel Alamantie vel Turpie mercatil, quas convenio vobis et vestris aportare ad meam missionem ad Alcol; quod vinum bonum et mercantil convenio vobis aportare usque ad medietatem Quadragesime venientem vel interim sine impedimento Dei, et dabitis mihi pro unaquaque migerola dicti vini tres bisancios et octo millarenses boni argenti et pensi, et dimiseritis mihi terciam partem botarum, et persolveritis mihi totam sumam peccunie de precio dicti vini usque ad XX dies postquam fuero applicatus cum dicto vino ad Alcol. Et convenio vobis et vestris hec attendere et complere ut superius dictum est sine impedimento Dei ad vestram voluntatem, obligando vobis et vestris me et omnia mea bona ubique. Et iuro in Deum et super sancta IIIlor evangelia mea manu propria tacta hec vobis fideliter attendere et complere ad vestram voluntatem.

Et nos Guillelmus Columbi et Bernardus de Rubi predicti laudamus hec supradicta et convenimus tibi Bernardo de Rivosicco et tuis predictum vinum recipere, ut dictum est, et precium predicti vini persolvere et reddere terciam partem botarum, ut lam superius est dictum, sine excusatione et dilacione, obli- 
gando tibi et tuis nos et omnia bona mea mobilia et inmobilia, habita et habenda ubique; et renunciamus super hec beneficio dividendo accionis. Et juramus in Deum et super sancta IIIlor Dei evangelia nostris propriis manibus tacta hec fideliter attendere et complere ad tuam voluntatem.

Actum est hoc in Tunicio II nonas novembris anno Domini M CC $L$ sexto. Signum Bernardi de Rivosicco. Signum Guillemi Columbi. Signum Bernardi de Rubi, qui hec firmamus et laudamus et juramus. Huius rei testes sunt Guillelmi Calderon, Bernardi Blader, Bernardi de Solerio. Signum Guillelmi Guardietii, publici Barchinone notarii, qui hoc scripsit et clausit.

$$
-2-
$$

1258, mayo, 24, Túnez

Contrato de fletamiento entre Pere Bonfill y Pere Llobregat, «senyors de la nau» Sant Miquel, y Arnau Bardoner, Bernat de Boaria, Pere de Prat, Ramon de Girona, Bernat de Roquet y Bernat Prim, mercaderes; que en total cargarán 670 quintales repartidos entre diversas mercancías: dátiles, cera, pimienta, alumbre,...etc. El recorrido será desde Túnez hasta Montpelier.

A.C.B., perg. 1-6-1303.

Sit omnibus notum quod nos Petrus Bonusfili, civis Barchinone, et Petrus de Lobregat, domini navis vocate Sanctum Michaelem uterque nostrum in solidum promittimus vobis Arnaldo Bardonerii et Bernardo de Boaria, Petro de Prato, Raimundo de Girunda, Bernardo de Roqueto atque Bernardo Prim, merchatoribus, deferre in dicta nave bene exarciata et amarinata cum viginti marinariis sufficientibus movendo de porto Tunicii et eundo Deo volente ad gradum Montipesulani, videlicet sexentos septuaginta quintariosx mercatarie subscripte de quibus sunt dictorum Petri de Prato et Rayundi de Girunda CCCC. Item Arnadil Bardonerii et Bernardi de Boaria C. Item Bernardi Prim $C$ et resudui LXX dicti Bernardi de Roquet, de quibus DCLXX quintariis dabitis nobis pro nolito de unoquoque coriorum bovum prout decenderit de ferro, VI miliarenses. Item de cimino (sic) VII miliarenses. Item de orchica VI miliarenses. Item de alumine IIII miliarenses. Item de dactilibus VI miliarenses. Item cera, piper, ginziber quisque VI miliarenses. Item indi VII miliarenses. Quibus iamdictis DCLXX quintariis possitis augere terciam partem infra $X V$ dies proxime venturus, quibus transactis vobis non teneamini de augmento. Quod dictum nolitum nobis solvetis infra Tunici et sumus tam nos quam vos expediti de Tunici ad faciendam dictum viaticum ab hinc usque ad festum Santi lohannis iunii proxime venturum. Ad hoc nos universi predicti merchatores promittimus 
vobis iamdictis dominis dicte navis universa predicta sub predictis pactis fideliter atender et complere, sub obligatione omnium bonorum nostrorum habitorum et habendorum ubique. Actum est hoc in Tunicio, IX kalendas iunii anno Domini millesimo CC Lo octavo. Signum Petri Bonifilii. Signum Petri de Lobregat. Signum Arnaoldi Bardonerii. Signum Bernardi de Boaria. Signum Petri de Prato. Signum Raimundi de Girunda. Signum Bernardi de Roqueto. Signum Bernardi Prim predictorum qui hoc laudamus et firmamus. Testes sunt Berengarius de Periliata, consul Catalanorum, atque Johannes Gasc. Signum Guillelmi Rostagni, notarii publici Mayorice, qui hoc scripsit.

\section{$-3-$}

1258, mayo, 26, Túnez

Venta de la tarida "Sanctus Michael» de los genoveses Ansaldus Ricius y Ansaldus Portonarius, al barcelonés Pere bonfill y a su socio Pere de Llobregat, de Mallorca, por 1.250 milareses, transacción efectuada en la nueva alhóndiga de los genoveses.

A.C.B., perg. 1-6-1682.

In nomine Domino. Nos Ansaldus Ricius et Ansaldus Portonarius quosque pro medietate vendimus, cedimus et tradimus vobis Petro Bonofilio, barcelonensi, et Petro de Lubregato, de Maiorica, taridam nostram minus sexterium que vocatus «Sanctus Michael», cum parte sarcie et barcharum ipsius taride pertinenti dicte taride minus sextum finito precio bisanciorum mille ducentorum quinquaginta bonorum millarensium, videlicet tibi Petro Bonofilio partes duas dicte taride et tibi Petri de Lubregato sextam partem, quos pro inde a vobis recepisse et habuisse confitemur et de quibus nos bene quietos et solutos vocamus, renunciantes excepcione non acceptorum et non habitorum biscanciorum vel precii non soluti, doli, condicioni sive causa et omni iuri. Si vero plus valet dicto precio, sciente etiam plus valere ipsumque plus et arbores et timonos vobis donamus et remittimus pura donacionem inter vivos, renunciantes iuri quo subvenitur deceptis in re vendita ultra dimidiam iusti precii possessionem et dominium, vobis exinde confitemur corporaliter tradidisse, constituentes nos pro vobis nomine precario possidere quamdiu possederimus, data vobis licencia accipiendi corporalem possessionem quandocumque vobis placuerit et de vestra fuerit voluntate pro supradicto precio et ex dicta causa damus, cedimus et tradimus vobis omnia iura omnesque raciones et acciones, utiles et directas, reales et personales et mixtas, que et quas habemus et nobis competunt et competere possent in dicta tarida minus sex- 
tum et sarcia et apparatu dicte parti continenti et contra omnem personam eius occassione, talier quod ipso iure et accionibus uti possitis agendo et defendendo et modis omnibus faciendo quibuscumque possumus vel possemus seu unquam potuimus, etad ea ut in rem vestram vos procuratores constituimus dictam preteream taridam minus sextum cum eius sarcia vel aliquid ex iure supradicto a vobis de cetero non impedire nec subtrahere promittimus inmo pocius ad omni persona ubique legitime defendere et auctorizare nostris propriis expensis remissa nobis necessitate de nonciandi. Si vero, ut supradictum est, per singula non observaverimus et observatum non erit vel in aliquo de predictis fuerit contrafactum, penam dupli de quanto dicta tarida minus sexta cum eius sarcia et apparatu nunc valet vel pro tempore melius valuerit vobis stipulantibus promittimus ratis semper manentibus omnibus et singulis supradictis, et proinde omnia bona nostra habita et habenda vobis pignori obligamus.

Testes Raimundus de Girona et Petrus de Prato et Marchisinus Galeta et Benevenutus de Quarto.

1258, agosto, 6. Túnez

Contrato de fletamento estipulado entre los propietarios de la nave «Sant Miquel» y Berenguer de Reguers, en el cual se fija el pago de 6 millareses por quintal barbaresco de carga.

A.C.B., perg. 1-6-1541.

Sit omnibus notum quod nos Petrus Bonifilii et Petrus de Lobregat, domini navis vocate «Sanctum Michaelem», promittimus tibi Berengario de Regueriis existenti in Tunicio, quod, si ego dictus Petrus Bonifili possum in venire illud manulavamentum quod michi comisisti cum publico instrumento, quod nos emamus et deferamus tibi in dicta navi in Tunicio omnia illa avera seu merces quas proposvimus ad in vicem cum memoriali per alphabetum diviso; ita quod dabis nobis pro nolito de unoquoque quintario barbareso infra Tunicio sex milarenses et medium argenti et insti ponderis. Ad hoc ego dictus Berengarius de Regeriis promitto vobis iamdictis Petro Bonifilii et Petro de Lobregat predictum nolitum solvere voluntati vestre sub predictis pactis, obligantes inde ad invicem omnia bona nostra habita et habenda ubique.

Actum est in Tunicio VIII idus augusti anno Domini millesimo CCo Lo octavo. 
Signum Petri Bonifilli. Signum Petri de Lubricato.

Signum Berengarii de Regeriis predicti, qui hoc laudamus et firmamus. Testes sunt Petrus Ferrarii, Bernardus de Mola atque Raimundus Mir.

Signum Guillelmi Rostagni, notarii publici Mayoricarum, qui hoc scripsit.

$$
-5-
$$

1266, septiembre, 15

Contrato de fletamiento con pago anticipado del flete, entre Bernat Ferrer, de Mallorca, con su leño llamado "Sancto Angelo", en viaje de Túnez a Barcelona, y Pere Bonfill y Pere Janer, de Barcelona.

A.C.B., perg. 1-6-39.

Sit omnibus notum, quod ego Bernardus Ferrarii, civis Maiorice, convenio et promitto et firmiter teneor per firmam stipulacionem et pactum expresum vobis Petro Bonifilii et Petro Januarii, civibus Barchinone, quod in presenti viatico, quod nunc facturi estis, domino concedente, cum ligno meo vocato Sancto Angelo, de portu Tunicii apud Barchinonam, portabo pro vobis et ad opus vestris in dicto ligno meo, bene exarciato, parato et amarinato cum octo marinariis et uno servicili, tot quintaratas mercium, scilicet, coriorum bovum, buchinarum vel de cera sive de cumino, quot et quantas in dicto ligno meo mitere volueritis, vos vero dando inde michi pro quolibet quintale quinque milarenses argenti fini iustique pensi, sicut cadit de ferro. Promittens vos expectare et esse me expeditum a Tunicio per totum mensem septembris, in quo nunc sumus. Promitto etiam vobis, quod non possim intrare in aliquo portu ultra vestri voluntatem. Quod nauleum supradictum solvatis mihi antequam a Tunicio recedamus ad meam voluntatem et mandatum. Intelligatur tamen, quod possim nauliejare et portare usque ad XV personas tantum. Et sic omnia supradicta vobis attendere et observare promito; promitens etiam vobis, quod de predictis non me extraham nec extrahi aliquo modo permitam, immo vos et merces vestras promito procurare, manutere et deffendere contra omnes personas toto posse meo. Et nisi predicta vobis adimpleverim, promitto dare pro pena centum bisancios argenti fini iustique pensi, qua pena detur domino regi Aragonie. Obligans inde vobis et vestris propter hec me et omnia bona mea mobilia et inmobilia, habita et habenda ubique, in quibus magis et melius accipere volueritis, sine vestro dampno; renuncians quantum ad hec ex certa sciencia omni iuri, racioni et consuetudini contra hec repugnantibus. 
Ad hec nos Petrus Bonfilii et Petrus Januarii convenimus et promittimus tibi dicto Bernardo Ferrarii, solvere et deliberare, tuis et cui volveris, dictum nauleum pro omnibus mercibus quibus in dicto ligno tuo mitemus vel miti faciemus, ad tuam voluntatem et mandatum, antequam a Tunicio recedamus, et omnia alia a nobis tibi atendenda atendere et complere. Et nisi predicta tibi adimpleverimus, promitimus dare et solvere pro pena centum bisancios argenti fini iustique pensi, qua pena detur domino regi Aragonie. Obligantes inde tibi et tuis propter hec nos et ominia bona nostra mobilia et inmobilia, habita et habenda ubique, in quibus magis et melius accipere volveris sine tuo dampno. Renunciantes quantum ad hec ex certa sciencia omni iuri, rationi et consutudini contra hec repugnantibus.

Actum est hoc in Tunicio .XVII. kalendas octobris anno Domini Mo.CCO.LXo sexto.

Signum Bernardi Ferrarii. Signum Petri Bonifilii. Signum Petri Januarii, nos qui predicta laudamus et firmamus.

Testes huius rei sunt Michael de Pontarró et Brandicius, cives Barchinone.

Signum Bartholomei Vaschonis, notarii publici Barchinone et Tunici, qui hoc scripsit et clausit die et anno prefixis.

$$
-6-
$$

1274, marzo, 19

Bernat Martorell y Pere Mataró reconocen que reciben una comanda de Joan de Banyeres para un viaje a Málaga y a otros lugares de Barberia, 63 libras y 5 sueldos invertidas en trigo, algodón, etc., en un común valorado en más de 726 libras. Este viaje se hace con la nave de Pere Mataró y sus socios.

A.C.B., perg. 1-6-2916.

Sit omnibus notum quod nos Bernardus Martorelli et Petru Maratoni confitemur et recognoscimus tibi Johanni de Bagneariis et tuis nos in tua comanda recepisse in presenti viatico quod facimus apud Malicham vel ad partes Barbarie in ligno mei dicti Peri Maratoni et sociorum vel in quocumque loco dictum lignum portum faciat causa mercanti sexaginta tres libras et quinque solidos monete Barchinonensis de teerno implicatas in comuni quod nobiscum portamus in dicto ligno, quod est de frumento, cotono, indio, lacha et aliis rebus, et constat dictum comune septigentas viginti sex libras et sexdecim solidos et octo denarios dicte monete, unde nos renunciantes excepcioni peccunie non numerate. Promittimus dictum comune illuc vendere bene et 
legaliter prout melius poterimus bona fide et precimum implicare sicut melius videamus et cognoscamus in utilibus implicamentis et quod se continget de dictis implicamentis racione dictarum sexaginta trium librarum et quinque solidorum. Convenimus in tuum tuorumque posse reducere facto dicto viatico sicut Deus ea salvaverit et esse tibi et tuis super predictis fideles in omnibus et legales et reddere inde tibi rectum computum et legale, de lucro vero quod Deus in hac comanda dederit deducto prius tuo capitali habeamus non quartam partem et tu tres partes cum tuo capitali set hec comanda maneat ubique ad voluntatem Dei et tui redegum et fortunam. Et pro hiis omnibus complendis ac firmiter attendendis obligamus tibi et tuis uterque nostrum in solidum nos et omnia bona nostra mobilia et inmobilia; renunciantes super hiis nove constitucione et benefficio dividende accionis, ac omni alii iuri, racioni et consuetudine conra hec repugnantibus. Actum est hoc .XIllo. kalendas aprilis Anno Domino .Mo.CCo.LXXo.tercio.

Signum Bernardi Martorelli. Signum Petri Mataroni predictorum, qui hoc laudamus et firmamus. Testes huius rei sunt Bernardus Rogerii et Bernardus de Sancto Cocuphate.

Sig-(signo)- + num Berengarii Lupeti, notarii publici Barchinoen, qui hoc scribi fecit et clausit die et anno quo supra.

1281, abril, 28

Jaume de Prat reconoce tener en comanda de Bonanat Soler y de los suyos, en el viaje que hace hacia Ibiza y de aqui a Togo,( $\left(^{*}\right.$ en la barca de Guillem de Gaià y socios, 52'5 sueldos en moneda de Barcelona de terno, de los que 42 '5 están implicados en cuchillos y los restantes 10 en un fustany. Promete venderlos e implicar lo obtenido conjuntamente con sus mercancias.

\section{ARXIU PARTICULAR DEL CASTELL DE VILASSAR.}

Sit omnibus notum quod ego, Jacobu de Prato, confiteor et recognosco tibi Bonanato de Solerio et tuis quod porto in tua comanda in presenti viatico quod facio aput Evissam et de Evissa aput Togo, in barcha Guillelmi de Gayano et sociorum, vel ubicumque dicta barcha portum fecerit causa mercandi, quinquaginta duos solidos et medium bone monete Barchinone, perpetue de terno de quibus sunt implicati quadraginta duo solidi et medii in cutellis et residui decem solidi in uno capite fustaney quod est Guillelmi de Prato, que implicamenta renunciando excepcioni pecunie non numerate et comande non recepte. Promito illuc vendere sicut melius potero bona fide. Et pretium quod 
inde habuero ibidem fideliter implicare simul cum rebus meis. Et ipsa implicamente capitale scilicet et lucrum facto dicto viatico sicut deo ea salvavit in tuum pose vel tuorum fideliter reducere scilicet partem tuam. Ita tamen quod de omni lucro quod Deus in hac comanda dederit deducto prius tuo capitali, deducto prius tuo capitali (sic) habeam ego quarta parte et tu residuas tres partes cum predicto tuo capitali. Set hac comanda eat, maneat ac redeat ubique ad voluntatem Dei et tui redegum et fortunam. Pro salvatione vero et restitucione huius comande sub forma premissa, obligo tibi et tuis me et omnia bona mea mobilia et inmobilia habita et habenda. Actum est hoc .IIIl. kalendas may Anno Domini .Mo.CCo.LXXXo. primo. Signum Jacobi de Prato, qui hoc laudo et firmo. Testes huius rei sunt Petrus de Prato cotellanius et Guillelmus de Monteacuto.

Sig + num Berengarii Guilaberti, notarii publici Barchinone, qui hoc scribi fecit et clausit. Die et anno, quo supra.

(*) BATLLE, C. BUSQUETA, J. CUADRADA, C. Notes sobre l'eix comercial Barcelona-Mallorca-Barbaria, a la segona meitat del segle XIII, comunicació al XIII Congrés d'História de la Corona d'Aragó, Mallorca, 1987, en prensa. Tratan el problema de Togo y publican este documento. 